\title{
Correction to: Requests for somatic support after neurologic death determination: Canadian physician experiences; Demandes de soutien des fonctions vitales après un diagnostic de décès neurologique : les expériences des médecins canadiens
}

\author{
Amanda van Beinum, MSc $\mathbb{D} \cdot$ Andrew Healey, MD · Jennifer Chandler, LLM • Sonny Dhanani, MD • \\ Michael Hartwick, MD, MEd • Ariane Lewis, MD • Calista Marshall, BSc · Jocasta Marshall, LLB • \\ Sam Shemie, MD · Jeffrey M. Singh, MD, MSc
}

Published online: 24 November 2020

(C) Canadian Anesthesiologists' Society 2020

\section{Correction to:}

Canadian Journal of Anesthesia/Journal canadien d'anesthésie https://doi.org/10.1007/s12630-020-01852-9

The ESM was updated in the original article to replace an incorrect version that was published with tracked changes notes.

The original article can be found online at https://doi.org/10.1007/ s12630-020-01852-9.

A. van Beinum, MSc $(\bowtie)$

Department of Sociology and Anthropology, Carleton University, B750 Loeb Building, 1125 Colonel By Drive, Ottawa, ON K1S 5B6, Canada

e-mail: amanda.vanbeinum@carleton.ca

A. Healey, MD

Critical Care, William Osler Health System, Brampton, ON,

Canada

Division of Emergency Medicine, McMaster University,

Hamilton, ON, Canada

J. Chandler, LLM

Centre for Health Law, Policy and Ethics, Faculty of Law,

University of Ottawa, Ottawa, ON, Canada

S. Dhanani, MD

Department of Critical Care, Children's Hospital of Eastern

Ontario, Ottawa, ON, Canada

Faculty of Medicine, University of Ottawa, Ottawa, ON, Canada

M. Hartwick, MD, MEd

Department of Medicine, University of Ottawa, Ottawa, ON, Canada
Publisher's Note Springer Nature remains neutral with regard to jurisdictional claims in published maps and institutional affiliations.

Divisions of Critical Care and Palliative Medicine, The Ottawa Hospital, Ottawa, ON, Canada

A. Lewis, MD

Departments of Neurology and Neurosurgery, Affiliate of the Department of Population Health-Division of Medical Ethics, NYU Langone Medical Center, New York, NY, USA

C. Marshall, BSc

Royal College of Surgeons, Dublin, Ireland

J. Marshall, LLB

St. George's University School of Medicine, St. George's, Grenada

S. Shemie, MD

Division of Pediatric Critical Care, Montreal Children's Hospital, McGill University Health Centre, Montreal, QC, Canada

J. M. Singh, MD, MSc Interdepartmental Division of Critical Care Medicine, University of Toronto, Toronto, ON, Canada 